\title{
Fat mass and obesity-associated gene rs11642015 polymorphism is significantly associated with prediabetes and type 2 diabetes subsequent to adjustment for body mass index
}

\author{
LIYUAN HAN $^{1 *}$, LINLIN TANG $^{1 *}$, CHANGYI WANG $^{2}$, ZHONGWEI CHEN $^{2}$, TAO ZHANG $^{2}$, SIHAN CHEN $^{2}$, \\ SHENGYUAN LIU ${ }^{2}$, XIAOLIN PENG ${ }^{2}$, YIFENG MAI ${ }^{3}$ and SHIWEI DUAN ${ }^{1}$ \\ ${ }^{1}$ Zhejiang Provincial Key Laboratory of Pathophysiology, Diabetes Center, School of Medicine, Ningbo University, \\ Ningbo, Zhejiang 315211; ${ }^{2}$ Shenzhen Nanshan Center for Chronic Disease Control, Shenzhen, Guangdong 518054; \\ ${ }^{3}$ The Affiliated Hospital, School of Medicine, Ningbo University, Ningbo, Zhejiang 315000, P.R. China
}

Received April 8, 2014; Accepted May 15, 2014

DOI: $10.3892 /$ br.2014.293

\begin{abstract}
The association of the fat mass and obesity-associated gene (FTO) rs11642015 polymorphism with prediabetes, type 2 diabetes and obesity in certain populations has not been previously reported. A population-based study was conducted that included 490 type 2 diabetic, 471 prediabetic and 575 normal subjects. The main outcomes of the study were prediabetes, type 2 diabetes and obesity. Binary logistic regression was performed to estimate the association of FTO rs11642015 with the risk of prediabetes, type 2 diabetes and obesity following adjustment for the corresponding confounders. A meta-analysis was also conducted to evaluate the association between FTO rs11642015 and obesity. FTO rs11642015 was significantly associated with prediabetes in the whole sample under the additive model [odds ratio (OR), 1.50; $95 \%$ confidence interval $(\mathrm{CI}), 1.17-1.93 ; \mathrm{P}=0.002]$, particularly in females. The polymorphism remained consistently significant following adjustment for age and body mass index (BMI), showing an increased prediabetes risk with an additive effect (OR, 1.55; 95\% CI, 1.19-2.01; $\mathrm{P}=0.001)$. In addition, a significant association was found for rs11642015 with prediabetes and type 2 diabetes under the dominant model. However, under the stringent Bonferroni's correction there was no evidence of positive associations for FTO rs11642015 with obesity in the
\end{abstract}

Correspondence to: Dr Liyuan Han or Dr Shiwei Duan, Zhejiang Provincial Key Laboratory of Pathophysiology, Diabetes Center, School of Medicine, Ningbo University, 818 Fenghua Road, Ningbo, Zhejiang 315211, P.R. China

E-mail: hanliyuan@nbu.edu.cn

E-mail: duanshiwei@nbu.edu.cn

*Contributed equally

Key words: type 2 diabetes, rs11642015, prediabetes, fat mass and obesity-associated gene, body mass index whole sample, females or males. Findings of the meta-analysis showed that FTO rs11642015 was not predisposed to obesity. In conclusion, the T allele of FTO rs11642015 is positively associated with an increased risk of prediabetes, even after adjustment for age and BMI, particularly in females. Subjects carrying the CT + TT genotype are predisposed to prediabetes and type 2 diabetes. Therefore, results of the population-based study and follow-up meta-analysis suggested that FTO rs11642015 is not significantly associated with susceptibility to obesity.

\section{Introduction}

The prevalence of diabetes is on the increase worldwide (1) and the global incidence and prevalence of type 2 diabetes in adolescents varies substantially in different countries and ethnicities (2). The estimated prevalence of diabetes and prediabetes was 11.6 and $50.1 \%$, respectively, in a representative sample of Chinese adults, and these figures may account for up to 113.9 and 493.4 million Chinese adults with diabetes and prediabetes, respectively (3).

The fat mass and obesity-associated (FTO) gene is situated on chromosome 16q12.2 and is composed of nine exons (4). FTO is highly expressed in rat hypothalamus (5), a brain structure involved in the regulation of energy balance and appetite $(5,6)$. Two independent genome-wide association studies (GWASs) indicated that a number of common variants (including rs9939609) in the first intron of FTO have the most significant effect on body mass index (BMI) and susceptibility to obesity, particularly in Europeans $(7,8)$. Since then, the majority of follow-up genetic studies have focused on FTO rs9939609, and the positive association between rs9939609 and type 2 diabetes has been shown to be entirely mediated through the effect of FTO on obesity (9).

Recently, Sällman Almén et al (10) sequenced 412 kilo base pairs of the genome, which covered the complete FTO gene in 524 severely obese children and 527 lean controls with massive parallel sequencing, following adjustment for the 44 haplotype blocks in the FTO region. Three single-nucleotide polymorphisms (SNPs) (rs55872725, rs11642015 and rs62048402) were 
found to be associated with obesity $(\mathrm{P}<0.0011)$. rs11642015 and rs62048402 were the top-associated SNPs and had a stronger obesity association $(\mathrm{P}<0.007)$ than the frequently studied rs9939609 $(\mathrm{P}<0.012)$. The study did not detect any strongly associated variants elsewhere, and therefore it was concluded that intron one was the only obesity-associated region of the FTO gene (10). Additionally, it was demonstrated that FTO rs11642015 was associated with obesity in Latvia (10), while Kalnina et al (11) demonstrated that the rs11642015, rs62048402 and rs9939609 polymorphisms in the first intron of FTO contributed to risk of type 2 diabetes, even following the correction for BMI.

Obesity is a major predictor of the risk of type 2 diabetes (12). FTO was initially identified as a type 2 diabetes susceptibility gene. However, further adjustment for BMI eliminated any significant association with type 2 diabetes (9). The association of the $F T O$ variants with type 2 diabetes and BMI has been mostly identified in Europeans (7). However, Meyre (13) examined whether FTO was a type 2 diabetes susceptibility gene. Further studies that focus particularly on different ethnicities are required to investigate this hypothesis. As the association between the FTO variants and risk of type 2 diabetes varied between ethnicities, conducting relevant future studies in subjects with different ethnic backgrounds is important.

As the association of FTO rs11642015 with the risk of prediabetes, type 2 diabetes and obesity in the Chinese population remains unclear, 490 type 2 diabetic, 471 prediabetic and 575 healthy subjects who originated from Shenzhen (China) were recruited. The results were also combined with those from two previously published studies $(10,14)$ to establish the contribution of FTO rs11642015 to susceptibility to obesity.

\section{Patients and methods}

Participants. The study was a population-based case-control study, in which 1,516 individuals (490 type 2 diabetic, 471 prediabetic and 575 healthy subjects) were consecutively recruited between April 2010 and September 2011. All the subjects were from 16 Community Health Service Centers (Nanshan, China) under the supervision of the Shenzhen Nanshan Center for Chronic Disease Control (Guangdong, China). A two-stage sampling method and a simple random procedure according to the sequence of computer-generated random numbers were applied. The study was approved by the Ethics Committee of Shenzhen Nanshan Center for Chronic Disease Control and all participants provided written informed consent. The BMI was calculated by the weight $(\mathrm{kg}) /$ height $\left(\mathrm{m}^{2}\right)$. The obesity (BMI $\left.\geq 28 \mathrm{~kg} / \mathrm{m}^{2}\right)$, overweight $\left(24 \leq \mathrm{BMI}<28 \mathrm{~kg} / \mathrm{m}^{2}\right)$ and normal weight $\left(\mathrm{BMI}<24 \mathrm{~kg} / \mathrm{m}^{2}\right)$ classes were defined according to the definition proposed by the Working Group on Obesity in China (15). Type 2 diabetes and prediabetes were diagnosed according to the American Diabetes Association guidelines of 2010 (16).

Genotyping. Human genomic DNA was separated from peripheral blood samples using the nucleic acid extraction automatic analyzer (Lab-Aid 820; Zeesan Biotech, Xiamen, China) and all the DNA samples were stored in Tris-EDTA buffer. The DNA concentration was determined using the PicoGreen ${ }^{\circledR}$ double-strand DNA Quantification kit (Molecular Probes Inc., Eugene, OR, USA). All subjects were genotyped for FTO rs11642015 using the MassARRAY compact analyzer based on the chip-based matrix-assisted laser desorption ionization time-of-flight mass spectrometry platform (Sequenom Inc., San Diego, CA, USA). Polymerase chain reaction cycles were initiated with an initial denaturation stage at $94^{\circ} \mathrm{C}$ for $15 \mathrm{~min}$, followed by 45 cycles at $94^{\circ} \mathrm{C}$ for $20 \mathrm{sec}$ for denaturation, $56^{\circ} \mathrm{C}$ for $30 \mathrm{sec}$ for annealing, $72^{\circ} \mathrm{C}$ for $1 \mathrm{~min}$ for primer extension and $72^{\circ} \mathrm{C}$ for $3 \mathrm{~min}$ for a final extension. DNA amplification for the FTO rs11642015 genotyping was performed on 5\% of the total samples and were randomly selected for a second genotype. The results remained consistent.

Statistical analysis. Consistency of the genotype frequencies were assessed with Hardy-Weinberg equilibrium (HWE) and percentages were analyzed by the $\chi^{2}$ test. A one-way analysis of variance was used to compare the continuous variables among the three groups (Table I). Allele and genotype frequencies were compared between cases and controls with the $\chi^{2}$ test. Binary logistic regression analysis was used to estimate the association of FTO rs11642015 with the risk of prediabetes, type 2 diabetes and obesity, subsequent to adjustment for the corresponding confounders. To reduce type I error induced by multiple tests, Bonferroni's adjustment was applied to determine the significance thresholds. This employed the following formula to adjust the significance level and maintain an error rate of $0.05: 1-(1-\partial)^{1 / \mathrm{n}} . \mathrm{P}<0.008$ was adopted as the significant threshold (Tables II and III). Statistical analysis was performed with the SPSS package, version 17.0 (SPSS, Inc., Chicago, IL, USA). All tests were two-tailed and $\mathrm{P}<0.05$ was considered to indicate a statistically significant difference. Power analysis was performed using the Power and Sample Size Calculation software (version 3.0.43) designed by William D. Dupont and Walton D. Plummer Jr (17).

The meta-analysis was performed by Stata version 11.0 (Stata Corporation, College Station, TX, USA). The Z-test was used to calculate the P-value of the overall effect for the meta-analysis. The combined odds ratios (ORs) together with their $95 \%$ confidence intervals (CIs) were assessed with the random-effects method. The between-study heterogeneity was estimated by the $\chi^{2}$-based $\mathrm{Q}$ test (significance level, $\mathrm{P}<0.10$ ) and $\mathrm{I}^{2}$ statistics $\left(\mathrm{I}^{2}\right.$ values of $<25,25-75$ and $>75 \%$ were defined as low, moderate and high heterogeneity, respectively), which can be interpreted as the percentage of total variation across several studies due to heterogeneity. Publication bias was evaluated by Egger's regression test, Begg's adjusted rank correlation test and a funnel plot. A two-sided $\mathrm{P}<0.05$ was considered to indicate a statistically significant difference.

\section{Results}

Characteristics of subjects. The characteristics of individuals included in the study are shown in Table I. A total of 490 subjects with type 2 diabetes, 471 with prediabetes and 575 non-diabetic subjects were involved in the present study. The genotype frequencies were assessed by HWE (Table I).

Comparison of genotype and allele frequencies. A multivariate analysis with covariates of age and BMI revealed that 
Table I. Characteristics of the subjects.

\begin{tabular}{lccccc}
\hline Characteristic & Controls & Prediabetes & Type 2 diabetes & P1 & P2 \\
\hline Subjects, $\mathrm{n}$ & 575 & 471 & 490 & & \\
Female/male, $\mathrm{n}$ & $289 / 286$ & $241 / 230$ & $248 / 242$ & 0.81 & 0.91 \\
Age, years & $57.94 \pm 10.81$ & $61.39 \pm 11.43$ & $62.76 \pm 11.14$ & 0.001 & 0.055 \\
BMI, kg/m & $23.52 \pm 3.17$ & $25.28 \pm 3.82$ & $24.95 \pm 3.46$ & 0.001 & 0.143 \\
Female & & & & 0.001 \\
Age, years & $58.50 \pm 10.00$ & $61.66 \pm 10.43$ & $63.99 \pm 10.28$ & 0.001 & 0.01 \\
BMI, kg/m & $23.18 \pm 3.09$ & $25.18 \pm 4.04$ & $24.69 \pm 3.58$ & 0.001 & 0.12 \\
Male & & & & 0.001 \\
Age, years & $57.38 \pm 11.56$ & $61.10 \pm 12.42$ & $61.51 \pm 11.85$ & 0.001 & 0.70 \\
BMI, kg/m & $23.87 \pm 3.22$ & $25.37 \pm 3.59$ & $25.20 \pm 3.32$ & 0.001 & 0.59 \\
\hline
\end{tabular}

Groups were compared using one-way analysis of variance. P, P-value; P1, prediabetes vs. controls; P2, type 2 diabetes vs. prediabetes; P3, type 2 diabetes vs. controls; BMI, body mass index.

Table II. Comparison of genotype and allele frequencies between cases and controls in the whole sample, stratified by gender.

\begin{tabular}{|c|c|c|c|c|c|c|c|c|c|c|c|c|c|}
\hline \multirow{2}{*}{$\begin{array}{l}\text { FTO } \\
(\text { rs11642015) }\end{array}$} & \multirow[b]{2}{*}{$\mathrm{CC}, \mathrm{n}$} & \multirow[b]{2}{*}{$\mathrm{CT}, \mathrm{n}$} & \multirow[b]{2}{*}{$\mathrm{TT}, \mathrm{n}$} & \multirow[b]{2}{*}{$\chi^{2}$} & \multirow[b]{2}{*}{ P-value } & \multirow[b]{2}{*}{$\mathrm{C}, \mathrm{n}$} & \multirow[b]{2}{*}{$\mathrm{T}, \mathrm{n}$} & \multirow[b]{2}{*}{$\chi^{2}$} & \multicolumn{2}{|c|}{ OR $(95 \% \mathrm{CI})$} & \multicolumn{2}{|c|}{ OR $(95 \%$ CI $)$} & \multirow[b]{2}{*}{ HWE } \\
\hline & & & & & & & & & P-value & Unadjusted & P-value & Adjusted $^{\mathrm{a}}$ & \\
\hline \multicolumn{14}{|l|}{ Whole sample ${ }^{b}$} \\
\hline Controls & 435 & 111 & 7 & & & 981 & 131 & & & & & & \\
\hline Prediabetes & 330 & 121 & 18 & 12.86 & $0.002^{\mathrm{c}}$ & 781 & 157 & 9.94 & $0.002^{\mathrm{c}}$ & $1.50(1.17-1.93)$ & $0.001^{\mathrm{c}}$ & $1.55(1.19-2.01)$ & 0.97 \\
\hline Type 2 diabetes & 345 & 133 & 9 & 8.46 & 0.01 & 823 & 151 & 5.84 & 0.01 & $1.37(1.06-1.76)$ & 0.50 & $0.91(0.70-1.18)$ & \\
\hline \multicolumn{14}{|l|}{ Female } \\
\hline Controls & 218 & 57 & 5 & & & 493 & 67 & & & & & & \\
\hline Prediabetes & 162 & 66 & 11 & 7.97 & 0.01 & 390 & 88 & 7.93 & $0.005^{\mathrm{c}}$ & $1.66(1.17-2.34)$ & $0.006^{\mathrm{c}}$ & $1.64(1.14-2.34)$ & 0.57 \\
\hline Type 2 diabetes & 174 & 66 & 5 & 3.27 & 0.19 & 414 & 76 & 2.50 & 0.11 & $1.35(0.94-1.92)$ & 0.55 & $1.11(0.77-1.62)$ & \\
\hline \multicolumn{14}{|l|}{ Male } \\
\hline Controls & 217 & 54 & 2 & & & 488 & 58 & & & & & & \\
\hline Prediabetes & 168 & 55 & 7 & 5.38 & 0.06 & 391 & 69 & 3.94 & 0.04 & $1.48(1.02-2.15)$ & 0.06 & $1.44(0.98-2.14)$ & 0.49 \\
\hline Type 2 diabetes & 171 & 67 & 4 & 5.67 & 0.059 & 409 & 75 & 4.99 & 0.02 & $1.54(1.06-2.22)$ & 0.02 & $1.57(1.05-2.33)$ & \\
\hline
\end{tabular}

${ }^{\mathrm{a}}$ Adjusted for age and BMI. bominant model of rs11642015 (CT + TT vs. CC) showed a significant result for prediabetes vs. controls $(\mathrm{P}=0.004$; OR, 1.55; 95\% CI, 1.15-2.09) adjusted for age and $\mathrm{BMI}$; and for type 2 diabetes vs. controls $(\mathrm{P}=0.002 ; \mathrm{OR}, 1.58 ; 95 \% \mathrm{CI}, 1.17-2.12)$ adjusted for age and BMI. 'Significant results. OR, odds ratio; CI, confidence interval; FTO, fat mass and obesity-associated gene; HWE, Hardy-Weinberg equilibrium; BMI, body mass index.

FTO rs11642015 was significantly associated with the risk of prediabetes in the whole sample (T vs. C: OR, $1.55 ; 95 \% \mathrm{CI}$, 1.19-2.01; $\mathrm{P}=0.001 ; \mathrm{CC}$ vs. $\mathrm{CT}+\mathrm{TT}$ : OR, $1.55 ; 95 \% \mathrm{CI}$, 1.15-2.09; $\mathrm{P}=0.004$; Table II). A further breakdown analysis by gender showed that FTO rs11642015 was associated with prediabetes, OR, 1.66 ( $\mathrm{T}$ vs. C: $95 \% \mathrm{CI}, 1.17-2.34$; $\mathrm{P}=0.005$ ), in females. The significant results remained following adjustment of age and BMI (OR, 1.64; 95\% CI: 1.14-2.34; $\mathrm{P}=0.006$, Table II).

Statistically significant differences were observed in the genotype frequencies of rs11642015 between subjects with type 2 diabetes and controls in the whole sample, particularly under the dominant model following adjustment for age and BMI (OR, 1.58; 95\% CI, 1.17-2.12; $\mathrm{P}=0.002)$. Further gender-stratified analysis did not reveal any significant results (Table II). There was no association of rs11642015 with type 2 diabetes for the comparison of the $\mathrm{T}$ and $\mathrm{C}$ allele and the additional adjustment for age and BMI did not change the results (Table II). According to power calculations, the sample size provided a $67.2 \%$ power $(\partial=0.05)$ to detect a relative risk for rs11642015.

Breakdown analysis by the BMI categories (14) was then conducted. However, no significant associations were found under the stringent Bonferroni's correction (Table III).

To assess the contribution of FTO rs11642015 to obesity, a meta-analysis of the data was performed together with 
Table III. Association between FTO rs11642015 with obesity and Hardy-Weinberg equilibrium (HWE).

\begin{tabular}{|c|c|c|c|c|c|c|c|c|c|c|c|c|c|}
\hline \multirow{2}{*}{$\begin{array}{l}\text { FTO } \\
\text { (rs } 11642015)\end{array}$} & \multirow[b]{2}{*}{$\mathrm{CC}, \mathrm{n}$} & \multirow[b]{2}{*}{$\mathrm{CT}, \mathrm{n}$} & \multirow[b]{2}{*}{$\mathrm{TT}, \mathrm{n}$} & \multirow[b]{2}{*}{$\chi^{2}$} & \multirow[b]{2}{*}{ P-value } & \multirow[b]{2}{*}{$\mathrm{C}, \mathrm{n}$} & \multirow[b]{2}{*}{$\mathrm{T}, \mathrm{n}$} & \multirow[b]{2}{*}{$\chi^{2}$} & \multicolumn{2}{|c|}{ OR $(95 \% \mathrm{CI})$} & \multicolumn{2}{|c|}{ OR $(95 \% \mathrm{CI})$} & \multirow[b]{2}{*}{ HWE } \\
\hline & & & & & & & & & P-value & Unadjusted & P-value & Adjusted & \\
\hline \multicolumn{14}{|l|}{ Whole sample } \\
\hline Normal weight & 500 & 189 & 18 & & & 1189 & 225 & & & & & & 0.97 \\
\hline Overweight & 483 & 137 & 14 & 5.13 & 0.07 & 1103 & 165 & 4.52 & 0.03 & $0.79(0.63-0.98)$ & 0.03 & $1.55(1.19-2.01)$ & \\
\hline Obese & 127 & 39 & 2 & 2.18 & 0.33 & 293 & 43 & 1.79 & 0.18 & $0.77(0.54-1.10)$ & 0.20 & $0.91(0.70-1.18)^{\mathrm{a}}$ & \\
\hline \multicolumn{14}{|l|}{ Female } \\
\hline Normal weight & 274 & 106 & 7 & & & 654 & 120 & & & & & & 0.37 \\
\hline Overweight & 218 & 63 & 9 & 3.74 & 0.15 & 499 & 81 & 0.50 & 0.47 & $0.88(0.65-1.20)$ & 0.47 & $1.64(1.14-2.34)$ & \\
\hline Obese & 60 & 23 & 2 & 0.11 & 0.94 & 143 & 27 & 0.01 & 0.99 & $1.02(0.65-1.62)$ & 0.80 & $1.11(0.77-1.62)^{\mathrm{a}}$ & \\
\hline \multicolumn{14}{|l|}{ Male } \\
\hline Normal weight & 226 & 83 & 11 & & & 535 & 105 & & & & & & 0.33 \\
\hline Overweight & 265 & 74 & 5 & 5.00 & 0.08 & 604 & 84 & 4.44 & 0.03 & $0.70(0.52-0.96)$ & 0.03 & $1.44(0.98-2.14)$ & \\
\hline Obese & 67 & 16 & 0 & 4.96 & 0.08 & 150 & 16 & 4.21 & 0.04 & $0.54(0.31-0.94)$ & 0.04 & $1.57(1.05-2.33)^{\mathrm{a}}$ & \\
\hline
\end{tabular}

${ }^{\mathrm{a}}$ Adjusted for age. Subjects were classified as obese if $\mathrm{BMI} \geq 28 \mathrm{~kg} / \mathrm{m}^{2}$. Normal weight, $\mathrm{BMI}<24$; overweight, $24 \leq \mathrm{BMI}>28$; obese, BMI $\geq 28$. FTO, fat mass and obesity-associated gene; OR, odds ratio; CI, confidence interval; BMI, body mass index.

Table IV. Characteristics of studies assessing the association between FTO rs11642015 and obesity.

\begin{tabular}{|c|c|c|c|c|c|c|c|c|c|c|c|c|}
\hline \multirow[b]{2}{*}{ Authors (year) } & \multirow[b]{2}{*}{ Ethnicity } & \multirow{2}{*}{$\begin{array}{c}\text { Case/ } \\
\text { control, } \mathrm{n}\end{array}$} & \multicolumn{2}{|c|}{ BMI } & \multicolumn{3}{|c|}{ Case, $\mathrm{n}$} & \multicolumn{3}{|c|}{ Control, $\mathrm{n}$} & \multirow[b]{2}{*}{ OR $(95 \% \mathrm{CI})$} & \multirow[b]{2}{*}{ HWE Refs } \\
\hline & & & Case $^{a}$ & Control $^{\mathrm{b}}$ & $\mathrm{CC}$ & $\mathrm{CT}$ & TT & $\mathrm{CC}$ & $\mathrm{CT}$ & $\mathrm{TT}$ & & \\
\hline $\begin{array}{l}\text { Sällman Almén } \\
\text { et al (2013) }\end{array}$ & Swedish & $524 / 527$ & - & - & - & - & - & - & - & - & $1.29(1.15-1.46)^{\mathrm{c}}$ & - (10) \\
\hline $\begin{array}{l}\text { Rovite et al } \\
\text { (2014) }\end{array}$ & Latvian & $380 / 380$ & $44.5 \pm 5.0$ & $22.9 \pm 1.6$ & 107 & 184 & 89 & 80 & 192 & 108 & $1.27(1.04-1.56)^{\mathrm{c}, \mathrm{d}}$ & $0.75(14)$ \\
\hline $\begin{array}{l}\text { Present study } \\
\text { (2014) }\end{array}$ & Chinese & $188 / 712$ & $31.09 \pm 3.61$ & $21.76 \pm 1.63$ & 127 & 39 & 2 & 500 & 189 & 18 & $0.79(0.56-1.13)^{\mathrm{c}, \mathrm{e}}$ & 0.97 \\
\hline
\end{tabular}

${ }^{\mathrm{a}} \mathrm{Case}$, obesity; ${ }^{\mathrm{b}} \mathrm{Control}$, normal weight; ${ }^{\mathrm{c} A d d i t i v e ~ m o d e l ; ~}{ }^{\mathrm{d}} \mathrm{OR}$ was estimated following adjustment for age and gender; and ${ }^{\mathrm{e}} \mathrm{OR}$ was estimated following adjustment for age. -, not available. FTO, fat mass and obesity-associated gene; BMI, body mass index; OR, odds ratio; CI, confidence interval; HWE, Hardy-Weinberg equilibrium.

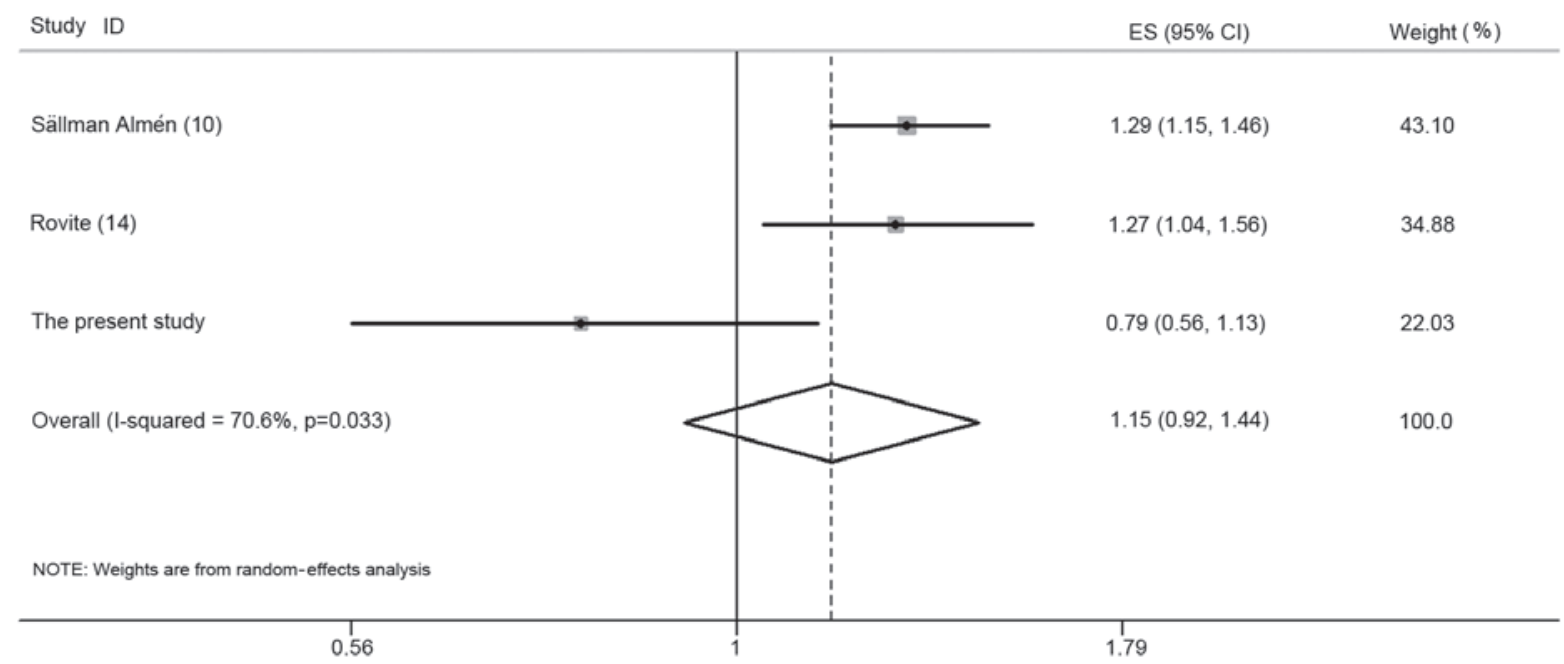

Figure 1. Meta-analysis plot for the association between fat mass and obesity-associated gene rs11642015 and obesity. 
data from two previous publications $(10,14)$. A meta-analysis suggested that the association between FTO rs11642015 and obesity under the additive model was not significant with high heterogeneity (OR, 1.15; 95\% CI, 0.92-1.44; $\mathrm{P}=0.21$; $\mathrm{P}_{\text {heterogeneity }}=0.03 ; \mathrm{I}^{2}=70.6 \%$; Fig. 1). There was no evidence of any publication bias observed (Begg's test $=0.29$ and Egger's test $=0.32$ ).

\section{Discussion}

The association between the FTO rs11642015 polymorphism with prediabetes, type 2 diabetes and obesity was examined in the present study, and to the best of our knowledge, the association has not been reported previously in the Chinese population. The association of the FTO locus with type 2 diabetes may vary in different populations.

The findings demonstrated that the FTO rs11642015 $\mathrm{T}$ allele was associated with the risk of prediabetes, particularly in females, and the association retained its significance following correction for age and BMI. Subjects carrying the $\mathrm{CT}+\mathrm{TT}$ genotype were predisposed to prediabetes and type 2 diabetes following correction for age and BMI. This was consistent with the study by Kalnina et al (11), in which FTO rs11642015 was linked with a higher type 2 diabetes prevalence and the significance was retained subsequent to correction for BMI.

Notably, a significant association was not observed between the FTO rs11642015 polymorphism and obesity in the whole sample, females and males under the stringent Bonferroni's correction. Under the stringent Bonferroni's correction, the correction may be extremely conservative and may increase the likelihood of type II error. In contrast to the present study, Sällman Almén et al (10) observed a stronger association of FTO rs11642015 with obesity compared to rs9939609 by massive parallel sequencing in Latvia. The minor allele frequency (MAF) observed in the present study was 0.18 for rs11642015, whereas the corresponding MAF in the study by Sällman Almén et al (10) was 0.48. The differences among the studies may be due to the differences in the risk allele frequencies and linkage disequilibrium structure across different ethnicities. Other reasons include the varying study designs, different sample sizes and ethnic differences in genetic background and environmental factors (18). Whether there was an association of the FTO rs11642015 with obesity was not clear, and therefore a meta-analysis was also conducted with available studies to provide more definitive evidence. The meta-analysis, including a total of 2,711 subjects, provided evidence that FTO rs11642015 is not associated with obesity.

Obesity is one of the most important risk factors for the development of type 2 diabetes (19). The most common genetic variant of the FTO gene is rs9939609, and the first GWAS detected the contribution of rs9939609 to type 2 diabetes. However, the significant association was not apparent following adjustment for BMI (9), indicating that the association between the FTO locus and type 2 diabetes was mediated by BMI and that FTO is a susceptibility locus for obesity instead of type 2 diabetes. Several studies have reported that the association between the FTO locus and risk of type 2 diabetes remained significant following adjustment for BMI (20-22). However, a recent study showed a significant association between the FTO rs9939609 polymorphism and type 2 diabetes in a Vietnamese population, independent of obesity-related measurements, socio-economic status and lifestyle factors (23). Findings of that study showed that the association between the FTO locus and type 2 diabetes was not completely moderated through BMI, as the accurate estimates may not be revealed in particular populations.

There have been fewer studies reported in South Asians. Of three studies that have been reported, there were two that confirmed the association between the FTO locus and obesity susceptibility $(24,25)$ and one that did not $(26)$. The association of the FTO variants with type 2 diabetes and BMI has been independently identified in a number of Caucasian European populations. However, Asians and Europeans have differences in body composition, and therefore, FTO may have a smaller effect on obesity in Asians compared to Europeans. A population-based homogeneous population with $100 \%$ Han Chinese was determined, which eliminated the ethnical heterogeneity. A group of prediabetes subjects were also included. The majority of the previous studies only focused on two groups (type 2 diabetes and non-diabetic subjects). Including the group of prediabetes subjects is useful for identifying high-risk individuals at early stages and providing improved early prevention. Identification of the FTO variations in multi-ethnic groups is useful for understanding the diverse genetic backgrounds in different ethnicities. Additionally, the P-values are also corrected for multiple comparisons to avoid false-positive associations.

However, there are certain limitations that require highlighting. Firstly, due to the cross-sectional design, the selection bias cannot be neglected. In addition, the sample size was relatively small and the power at $67.2 \%$ to detect the association. Thirdly, there is a possibility that the interaction between gene-gene or gene-environment factors may conceal the true effect of specific genetic variants.

In conclusion, a significant association of the FTO rs11642015 $\mathrm{T}$ allele was observed with prediabetes following correction for age and BMI, particularly in females. Subjects carrying the $\mathrm{CT}+\mathrm{TT}$ genotype are predisposed to a prediabetes and type 2 diabetes risk. Future investigation is required to elucidate the molecular function of FTO, downstream pathways and interactions, as well as the biological pathways that are fundamental for the independent association between the FTO variation with obesity and type 2 diabetes (27).

\section{Acknowledgements}

The authors are grateful to the doctors and nurses for their help in the data and sample collection at the Community Health Centers. The present study was supported by grants from the National Natural Science Foundation of China (grant nos. 31100919 and 81371469), the Natural Science Foundation of Zhejiang Province (grant no. LR13H020003), the K.C. Wong Magna Fund in Ningbo University and Ningbo Social Development Research Projects (grant no. 2012C50032), the Ningbo University Talent Project (grant no. ZX2012000046) and the Natural Science Foundation of Zhejiang Province (LQ13H260002), Zhejiang Province Scientific Research Projects of Education (no. Y201326971). 


\section{References}

1. Chen L, Magliano DJ and Zimmet PZ: The worldwide epidemiology of type 2 diabetes mellitus - present and future perspectives. Nat Rev Endocrinol 8: 228-236, 2011.

2. Fazeli Farsani S, van der Aa MP, van der Vorst MM, et al: Global trends in the incidence and prevalence of type 2 diabetes in children and adolescents: a systematic review and evaluation of methodological approaches. Diabetologia 56: 1471-1488, 2013.

3. Xu Y, Wang L, He J, et al; 2010 China Noncommunicable Disease Surveillance Group: Prevalence and control of diabetes in Chinese adults. JAMA 310: 948-959, 2013.

4. Fredriksson R, Hägglund M, Olszewski PK, et al: The obesity gene, FTO, is of ancient origin, up-regulated during food deprivation and expressed in neurons of feeding-related nuclei of the brain. Endocrinology 149: 2062-2071, 2008.

5. Cecil J, Dalton M, Finlayson G, et al: Obesity and eating behaviour in children and adolescents: contribution of common gene polymorphisms. Int Rev Psychiatry 24: 200-210, 2012.

6. Schmid PM, Heid I, Buechler C, et al: Expression of fourteen novel obesity-related genes in Zucker diabetic fatty rats. Cardiovasc Diabetol 11: 48, 2012.

7. Dina C, Meyre D, Gallina S, et al: Variation in FTO contributes to childhood obesity and severe adult obesity. Nat Genet 39: 724-726, 2007.

8. Scott LJ, Mohlke KL, Bonnycastle LL, et al: A genome-wide association study of type 2 diabetes in Finns detects multiple susceptibility variants. Science 316: 1341-1345, 2007.

9. Frayling TM, Timpson NJ, Weedon MN, et al: A common variant in the FTO gene is associated with body mass index and predisposes to childhood and adult obesity. Science 316 889-894, 2007.

10. Sällman Almén M, Rask-Andersen M, Jacobsson JA, et al: Determination of the obesity-associated gene variants within the entire FTO gene by ultra-deep targeted sequencing in obese and lean children. Int J Obes (Lond) 37: 424-431, 2013.

11. Kalnina I, Zaharenko L, Vaivade I, et al: Polymorphisms in FTO and near TMEM18 associate with type 2 diabetes and predispose to younger age at diagnosis of diabetes. Gene 527 462-468, 2013.

12. Abdullah A, Peeters A, de Courten M and Stoelwinder J: The magnitude of association between overweight and obesity and the risk of diabetes: a meta-analysis of prospective cohort studies. Diabetes Res Clin Pract 89: 309-319, 2010.

13. Meyre D: Is FTO a type 2 diabetes susceptibility gene? Diabetologia 55: 873-876, 2012.

14. Rovite V, Petrovska R, Vaivade I, et al: The role of common and rare MC4R variants and FTO polymorphisms in extreme form of obesity. Mol Biol Rep 41: 1491-1500, 2014.
15. Bei-Fan Z; Cooperative Meta-Analysis Group of Working Group on Obesity in China: Predictive values of body mass index and waist circumference for risk factors of certain related diseases in Chinese adults: study on optimal cut-off points of body mass index and waist circumference in Chinese adults. Asia Pac J Clin Nutr 11 (Suppl 8): S685-S693, 2002.

16. American Diabetes Association: Diagnosis and classification of diabetes mellitus. Diabetes Care 33 Suppl 1: S62-S69, 2010.

17. Dupont WD and Plummer WD Jr: Power and sample size calculations. A review and computer program. Control Clin Trials 11 $116-128,1990$.

18. Adeyemo A and Rotimi C: Genetic variants associated with complex human diseases show wide variation across multiple populations. Public Health Genomics 13: 72-79, 2010.

19. Weber MB, Oza-Frank R, Staimez LR, et al: Type 2 diabetes in Asians: prevalence, risk factors and effectiveness of behavioral intervention at individual and population levels. Annu Rev Nutr 32: 417-439, 2012.

20. Hertel JK, Johansson S, Sonestedt E, et al: FTO, type 2 diabetes and weight gain throughout adult life: a meta-analysis of 41,504 subjects from the Scandinavian HUNT, MDC and MPP studies. Diabetes 60: 1637-1644, 2011.

21. Liu Y, Liu Z, Song Y, et al: Meta-analysis added power to identify variants in FTO associated with type 2 diabetes and obesity in the Asian population. Obesity (Silver Spring) 18: 1619-1624, 2010.

22. Takeuchi F, Yamamoto K, Katsuya T, et al: Association of genetic variants for susceptibility to obesity with type 2 diabetes in Japanese individuals. Diabetologia 54: 1350-1359, 2011.

23. Binh TQ, Phuong PT, Nhung BT, et al: Association of the common FTO-rs9939609 polymorphism with type 2 diabetes, independent of obesity-related traits in a Vietnamese population. Gene 513: 31-35, 2013 .

24. Ramya K, Radha V, Ghosh S, et al: Genetic variations in the FTO gene are associated with type 2 diabetes and obesity in south Indians (CURES-79). Diabetes Technol Ther 13: 33-42, 2011.

25. Dorajoo R, Blakemore AI, Sim X, et al: Replication of 13 obesity loci among Singaporean Chinese, Malay and Asian-Indian populations. Int J Obes (Lond) 36: 159-163, 2012.

26. Yajnik CS, Janipalli CS, Bhaskar S, et al: FTO gene variants are strongly associated with type 2 diabetes in South Asian Indians. Diabetologia 52: 247-252, 2009.

27. Hess ME and Brüning JC: The fat mass and obesity-associated (FTO) gene: Obesity and beyond? Biochim Biophys Acta: Feb 8, 2014 (Epub ahead of print) doi: 10.1016/j.bbadis.2014.01.017. 